\title{
Remitting seronegative symmetrical synovitis with pitting oedema: disease or syndrome?
}

T Schaeverbeke, E Fatout, S Marcé, J-P Vernhes, O Hallé, J-F Antoine, L Lequen, B Bannwarth, J Dehais

\begin{abstract}
Objective-To evaluate the outcome of patients with remitting seronegative symmetrical synovitis with pitting oedema $\left(\mathrm{RS}_{3}\right.$ PE).

Methods-In a retrospective chart review study, we identified all the patients presenting with polyarthritis and pitting oedema in the past 20 years. We tried to recall the 24 patients with characteristics of $\mathrm{RS}_{3} \mathrm{PE}$ according to McCarty et al. Two patients had died and four could not be traced. Five could not be seen after the initial period of follow up; relevant data were obtained from their practitioner. For the remaining 13 patients, clinical, radiological, and biological evaluation was performed in our department, with the last assessment in 1993.
\end{abstract}

Results-The follow up period was from one to 18 years (mean 4.6 (SD 4.5 ) years). Eleven patients developed one or several recurrences of articular manifestations consisting of mild oligoarthritis $(n=8)$, definite spondyloarthropathy $(n=2)$, and rheumatoid arthritis $(n=1)$. The delay of the first recurrence was 18 months to 12 years after the first attack. Thirteen patients had no recurrence, but three of them developed remarkable features: rheumatoid factor, antinuclear antibodies (1/2000), Sjögren's syndrome. HLA B typing was performed in nine patients and revealed B7 $(n=2), B 27(n=2)$ and B22 $(\mathbf{n}=2)$. Isolated HLA B27 typing was performed in two other patients and was positive in one.

Conclusion-The long term outcome of $\mathrm{RS}_{3} P E$ can lead to different rheumatic diseases. $\mathrm{RS}_{3} \mathrm{PE}$ appears to be a syndrome related to the elderly onset of the rheumatic diseases, including spondyloarthropathy and rheumatoid arthritis, rather than a specific entity.

(Ann Rheum Dis 1995; 54: 681-684)

Remitting seronegative symmetrical synovitis with pitting oedema $\left(\mathrm{RS}_{3} \mathrm{PE}\right)$ was described in 1985 by McCarty et al as an original subgroup of seronegative rheumatoid arthritis. ${ }^{1}$ It occurred especially in men older than 60 . The onset of the disease was sudden and characterised by a symmetrical polyarthritis associated with pitting oedema of the extremities of the upper and lower limbs. Laboratory changes included a high sedi- mentation rate, but neither rheumatoid factor nor antinuclear antibodies (ANA). The disease was reported to be associated with the presence of HLA B7. ${ }^{1}$ There was no evidence of articular erosions on radiographs. The prognosis was good; remission occurred usually within 18 months. However, stiffness of the fingers persisted sometimes. ${ }^{1}$ The aim of this study was to assess the outcome of patients who presented with $\mathrm{RS}_{3} \mathrm{PE}$ in our department over the past two decades.

\section{Patients and methods}

In a retrospective chart review study, we identified 24 patients who presented to the department of rheumatology of Bordeaux University Hospital with $\mathrm{RS}_{3} \mathrm{PE}$ (diagnosed according to the description of McCarty et $\mathrm{al}^{1}$ ) (table 1). Their ages ranged from 60 to 86 years (mean 71.4 (SD 7.7) years) at the onset of the disease. An acute onset was noted in all cases, oedema and polyarthritis occurring concurrently. However, three patients (Nos 13, $16,18)$ complained of inflammatory pain and stiffness of the shoulders in the three weeks before distal arthritides and oedemas began. All the patients had a pitting oedema spreading on the dorsum of the hands and the distal part of the forearms. Oedema was located on both hands and feet in 20 patients, and only on the hands in four. All the patients had a symmetrical polyarthritis involving at least the two hands, with a marked tenosynovitis of the flexors of the fingers, leading to carpal tunnel symptoms in two (patients 16 and 21 ). The shoulders were involved in 16 patients, and the elbows in six. These joints were painful and stiff. Painful synovitis of the knees without effusion was observed in 12 patients, being symmetrical in nine of them. Only one patient (No 21) had an effusion of the knees; synovial fluid analysis showed 4000 cells $/ \mathrm{mm}^{3}$, with an equal number of neutrophils and lymphocytes. None of the patients had a past history of colitis, uveitis, inflammatory back pain, or heel pain or arthritis, except patient 17 who, three years earlier, had had a polymyalgia rheumatica associated with a biopsy proven giant cell arteritis resolving with corticosteroid treatment. He had not received any treatment for a period of one year when $\mathrm{RS}_{3} \mathrm{PE}$ occurred. None of the patients had a family history of any inflammatory rheumatic disease.

At the onset of the disease, the erythrocyte sedimentation rate (ESR) ranged from 6 to 110 $\mathrm{mm} / 1 \mathrm{st} \mathrm{h}$ (mean 66 (31) $\mathrm{mm} / 1 \mathrm{st} \mathrm{h}$ ). No patient was rheumatoid factor positive; 17 
Table $1 \quad R S_{3} P E$ study group: clinical and biological data at onset

\begin{tabular}{|c|c|c|c|c|c|c|c|c|c|c|c|c|c|c|c|c|}
\hline \multirow[t]{2}{*}{ Patient } & \multirow[t]{2}{*}{ Sex } & \multirow{2}{*}{$\begin{array}{l}\text { Age } \\
(y r)\end{array}$} & \multirow[t]{2}{*}{ Month } & \multicolumn{5}{|l|}{ Oedema } & \multicolumn{5}{|l|}{ Arthritis } & \multirow{2}{*}{$\begin{array}{l}E S R \\
(\mathrm{~mm} / 1 \mathrm{st} h)\end{array}$} & \multirow[t]{2}{*}{$A N A$} & \multirow[t]{2}{*}{$H L A A, B$} \\
\hline & & & & Hands & Feet & Shoulder & Elbow & Wrist & $M C P / P I P$ & Hip & Knee & Ankle & Feet & & & \\
\hline 1 & M & 73 & March & + & + & 2 & & 2 & 2 & & 2 & 2 & 2 & 94 & nd & nd \\
\hline 2 & M & 73 & September & + & + & & & 2 & 2 & & 2 & 2 & 2 & 40 & nd & nd \\
\hline 3 & M & 83 & January & + & & 2 & & 2 & 2 & & & & & 6 & nd & nd \\
\hline 4 & $M$ & 64 & December & + & + & 2 & & 2 & 2 & & 2 & 2 & 2 & 50 & nd & nd \\
\hline 5 & $M$ & 60 & June & + & + & & & 2 & 2 & & & & 2 & 16 & Negative & nd \\
\hline 6 & W & 83 & October & + & + & 2 & & 2 & 2 & & & 2 & 2 & 95 & nd & nd \\
\hline 7 & $\mathbf{M}$ & 72 & June & + & + & & & 2 & 2 & & & 2 & 2 & 81 & nd & nd \\
\hline 8 & $\mathbf{M}$ & 86 & February & + & + & & & 2 & 2 & & 1 & 2 & 2 & 33 & Negative & nd \\
\hline 9 & M & 66 & July & + & & 2 & & 2 & 2 & & & & & 74 & Negative & nd \\
\hline 10 & M & 70 & June & + & + & & & 2 & 2 & & 2 & 2 & 2 & 108 & Negative & A2, 11-B22, 41 \\
\hline 11 & $\mathbf{M}$ & 61 & November & + & + & 2 & 2 & 2 & 2 & & 2 & 2 & 2 & 20 & Negative & nd \\
\hline 12 & $M$ & 78 & December & + & + & 2 & 2 & 2 & 2 & & 1 & 2 & 2 & 99 & Negative & A3, 9-B7, 27 \\
\hline 13 & M & 76 & July & + & + & 2 & & 2 & 2 & 2 & & 2 & 2 & 51 & & nd \\
\hline 14 & $\mathbf{M}$ & 85 & May & + & & & 2 & 2 & 2 & & & & & 45 & Negative & nd \\
\hline 15 & M & 72 & August & + & + & 2 & 2 & 2 & 2 & & & 2 & 2 & 72 & Negative & nd \\
\hline 16 & M & 65 & January & + & + & 2 & & 2 & 2 & 2 & & 2 & 2 & 70 & $1 / 40$ & $\mathrm{~A} 1,2-\mathrm{B} 17,422$ \\
\hline 17 & $\mathbf{M}$ & 66 & July & + & + & 2 & & 2 & 2 & & 2 & 2 & 2 & 110 & Negative & $\mathrm{A} 2,29-\mathrm{B} 12,21$ \\
\hline 18 & W & 70 & September & + & + & 2 & 2 & 2 & 2 & & & 2 & 2 & 60 & $1 / 40$ & $\mathrm{~A} 11,00-\mathrm{B} 5,00$ \\
\hline 19 & $\mathbf{M}$ & 64 & May & + & + & & & 2 & 2 & & & 2 & 2 & 65 & Negative & B27+ \\
\hline 20 & M & 79 & June & + & + & 2 & & 2 & 2 & & 2 & 2 & 2 & 110 & $1 / 250$ & A2, 11-B8, 15 \\
\hline 21 & M & 65 & June & + & & 2 & 2 & 2 & 2 & & 2 & 2 & 2 & 96 & Negative & A2, 9-B12, 27 \\
\hline 22 & W & 67 & September & + & + & 2 & & 2 & 2 & & 2 & 2 & 2 & 55 & Negative & $\mathrm{A} 2,9-\mathrm{B} 18,35$ \\
\hline 23 & W & 71 & August & + & + & & & 2 & 2 & & 2 & 2 & 2 & 26 & $1 / 40$ & A2, 3-B5, 7 \\
\hline 24 & W & 65 & May & + & + & 2 & & 2 & 2 & & 1 & 1 & 2 & 97 & Negative & B27- \\
\hline
\end{tabular}

patients were screened for ANA and only one (No 20) had a significant level (1:250 dilution). HLA B typing was performed in nine patients. Radiography did not reveal any changes other than those characteristic of osteoarthritis in some patients. Radiographs of the pelvis did not show sacroiliitis. All the patients were treated with antimalarial drugs associated with either oral low dose prednisone (daily dose $\leqslant 10 \mathrm{mg}$ ) or various non-steroidal anti-inflammatory drugs (NSAIDs). They recovered within three to 17 months (mean $(4 \cdot 7)$ months) with resolution of oedema in the first month in all. We attempted to contact these patients to evaluate their long term outcome. Two had died of an unrelated disease (patients 5, 7) and four were not traced (patients 3, 4, 6, 8); the disease course of these six patients was evaluated only during the period of initial follow up in our department. Five other patients could not be seen after the initial period of follow up (patients $2,9,13,14$, 20 ), but relevant data were obtained from their practitioners. For the remaining 13 patients, clinical, radiological, and biological evaluation was performed in our department, with the last assessment in 1993.

\section{Results}

Table 2 summarises the results.

The follow up period varied from one to 18 years (mean $4.6(4.5)$ years). Eleven patients had at least one relapse. The time of the first relapse varied from 18 months to 12 years. This relapse consisted usually of a mild oligoarthritis $(n=8)$, well controlled by NSAIDs $(n=6)$ or low dose prednisone $(n=2)$. In one of these patients, the relapse was associated with pitting oedema. Two other patients presented with definite spondyloarthropathy according to Amor's criteria; ${ }^{2}$ another developed typical rheumatoid arthritis. Thirteen patients did not suffer relapse but, in this group, rheumatoid factor became positive in one, ANA became strongly positive $(1 / 2000)$ in a second, and a third developed Sjögren's syndrome.

HLA A and B typing was performed in nine patients: two were HLA B7 positive; one of them was also B27 positive (this patient had radiographic sclerosis of the sacroiliac joints). Another B27 positive patient had a relapse of oligoarthritis with pitting oedema 18 months after the first episode. Two patients were HLA B22 positive. Another patient was HLA B35 positive; this patient developed a mild oligoarthritis. Of the two patients in whom only HLA B27 was sought, one patient was positive. He had some relapses of oligoarthritis, with neither sacroiliitis nor enthesitis. (The haplotype prevalences in our background white population are $21 \cdot 7 \%, 5 \cdot 5 \%, 6 \cdot 7 \%$, and $19 \cdot 9 \%$ for HLA B7, B22, B27, and B35, respectively.)

\section{Discussion}

Almost $50 \%$ of the patients who were diagnosed as having $\mathrm{RS}_{3} \mathrm{PE}$ developed features of specific rheumatic diseases: rheumatoid arthritis, spondyloarthropathy, or undifferentiated connective tissue disease. These results raise the question of whether $\mathrm{RS}_{3} \mathrm{PE}$ is a disease or a syndrome.

The major difficulty in the interpretation of our results lies in the definition of the disease. Do our $\mathrm{RS}_{3} \mathrm{PE}$ patients really have $\mathrm{RS}_{3} \mathrm{PE}$ ? There are no definite criteria for this condition, and $\mathrm{RS}_{3} \mathrm{PE}$ was diagnosed retrospectively in the first nine patients in our study. Our patients accorded with McCarty's description of $\mathrm{RS}_{3} \mathrm{PE}$ for age at onset of disease, gender ratio, the location of oedema, and type of articular involvement. They all recovered from the initial flare of the disease with anti-inflammatory drugs, associated with antimalarial drugs. McCarty's group prescribed chloroquine in five of their patients, whereas two others were given gold sodium thioglucose and three did not require a second line drug. ${ }^{1}$ All but one of their patients lived in a rural community, and 11 of 12 patients had a disease onset between 
Table 2 Immediate and long term outcome

\begin{tabular}{llll}
\hline Patient & $\begin{array}{l}\text { Time to } \\
\text { resolution of } \\
R S_{3} P E \text { (months) }\end{array}$ & $\begin{array}{l}\text { Follow up } \\
\text { (years) }\end{array}$ & Long term outcome \\
\hline 1 & 16 & 18 & Mild oligoarthritis 12 years after the onset \\
2 & 12 & 17 & No relapse \\
3 & 6 & $1 \cdot 5$ & Not traced after 18 months \\
4 & 10 & 1 & Not traced after 12 months \\
5 & 18 & 5 & No relapse. Dead \\
6 & 10 & $2 \cdot 3$ & RF + after eight months. Not traced after 27 months \\
7 & 5 & 3 & No relapse. Dead \\
8 & 12 & 3 & Not traced after three years. No relapse at this time \\
9 & 5 & 10 & No relapse \\
10 & 3 & 6 & RF + after one year. Mild oligoarthritis \\
11 & 5 & 6 & Seronegative oligoarthritis \\
12 & 6 & 6 & Spondyloarthropathy \\
13 & 14 & 4 & No relapse \\
14 & 8 & 4 & No relapse \\
15 & 6 & 3 & Mild erosive oligoarthritis (wrist, MCP) \\
16 & 12 & 3 & RF + after one year. Chronic polyarthritis \\
17 & 10 & 3 & Peripheral spondyloarthropathy. Erosive sacroiliitis \\
18 & 16 & 3 & Mild oligoarthritis \\
19 & 10 & $2 \cdot 5$ & Oligoarthritis. No sacroiliitis \\
20 & 5 & 2 & ANA 1/2000 after one year. No relapse \\
21 & 3 & 2 & Oligoarthritis + oedema after 18 months \\
22 & 17 & 2 & Mild oligoarthritis \\
23 & 10 & $1 \cdot 5$ & Sioggren's syndrome. No relapse \\
24 & 3 & 1 & No relapse \\
\hline
\end{tabular}

$\mathrm{RF}=$ rheumatoid factor; $\mathrm{MCP}=$ metacarpophalangeal joint.

May and November. ${ }^{1}$ In our series, 18 of 24 patients experienced onset of their disease during the same period, but only 11 of them lived in a rural community. It could be considered that the 13 patients who never relapsed had 'true' $\mathrm{RS}_{3} \mathrm{PE}$, while the 11 others had seronegative symmetrical synovitis with pitting oedema mimicking $\mathrm{RS}_{3} \mathrm{PE}$. However, there was no difference in the initial clinical features between our patients who did not relapse and the others. This would imply that it is necessary to allow a very long period to elapse before a diagnosis of true $\mathrm{RS}_{3} \mathrm{PE}$ could be made, as the underlying disease may reveal its identity after many years (up to 12 years in our study).

One of the main characteristics of $\mathrm{RS}_{3} \mathrm{PE}$ is the presence of pitting oedema. However, pitting oedema has been described in the elderly with other rheumatic disorders, including rheumatoid arthritis, ${ }^{3}$ and has also been noted in late onset peripheral spondyloarthropathy (LOPS). ${ }^{4}$ However, in LOPS, the oedema is not symmetrical and affects lower limbs rather than upper ones. Pitting oedema may also be noted in connective tissue disorders, such as systemic lupus erythematosus, systemic sclerosis, polymyositis and, most typically, overlap syndromes. ${ }^{6}$ The significance of this oedema is not clear. As there is no general reason for it (no cardiac or renal failure, no hypoalbuminaemia), a local phenomenon must be involved. A lymphatic involvement ${ }^{78}$ and a slowing in the lymphatic clearance $^{9}$ have been demonstrated in few cases of lymphoedema associated with rheumatoid arthritis. It has been suggested that the main cause of this oedema is a blockade of the deep lymph vessels. However, the treatment of rheumatoid arthritis does not significantly improve rheumatoid lymphoedema. ${ }^{10}$ The oedema of $\mathrm{RS}_{3} \mathrm{PE}$ is clearly different from lymphoedema: it is smooth, pitting oedema and it quickly improves with initiation of anti-inflammatory treatment. The oedema of $\mathrm{RS}_{3} \mathrm{PE}$ may be ascribed to an increase of the capillary permeability as a result of local inflammation; indeed, such changes in capillary permeability with increased filtration of tissue fluid have been reported in rheumatoid arthritis. ${ }^{11}$

The sudden onset and good prognosis of $\mathrm{RS}_{3} \mathrm{PE}$ have been emphasised. However, good prognosis seems to be a usual feature in elderly onset rheumatoid arthritis also. ${ }^{12}$ A subgroup of rheumatoid arthritis in the elderly was characterised by a sudden onset, a high incidence in men, and a total remission occurring within 12 to 18 months. ${ }^{13}$

Another peculiarity of the first patients with $\mathrm{RS}_{3} \mathrm{PE}$ described by McCarty et al, was the high incidence of the HLA B7 subtype (six of eight patients). A second paper from the same department, reporting 13 additional cases, again noted this frequency of HLA B7 haplotype (seven out of 13).${ }^{14}$ However, none of the four cases of $\mathrm{RS}_{3} \mathrm{PE}$ reported by Chaouat and Le Parc was B7 positive, ${ }^{3}$ and of our nine patients in whom HLA B was studied, only two were $B 7$ positive. Collation of all these data $(n=32)$ reveals the presence of the following types: B7 $(n=15), B 27(n=7), B 22$ $(n=2)$, B35 $(n=4)$, and DR7 $(n=4)$. The relationship of all these HLA subtypes with the spondyloarthropathies has been discussed. HLA B7, B22, and B27 belong to the B7 cross reactive group, ${ }^{15}$ the possible relationship of HLA B35 with the spondyloarthropathies has been reported, ${ }^{15}$ and the DR7 subtype is clearly related to peripheral spondyloarthropathy. ${ }^{16} 17$ Thus the prevalence of these different HLA subtypes may be considered as an argument for a spondyloarthropathy.

As all peripheral spondyloarthropathies are less related to the presence of HLA B27 than ankylosing spondylitis, it is feasible that peripheral spondyloarthropathy in the elderly is not highly related to HLA B27. LOPS, as described by Dubost $e t a l,{ }^{4}$ is closely related to the presence of HLA B27. However, to define this new syndrome, the authors have selected a group of patients in whom many elements of spondyloarthropathy are combined: 10 of 10 were HLA B27 positive, five had sacroiliitis, and nine fulfilled Amor's criteria for spondyloarthropathy. ${ }^{2}$ Probably, many other patients have an LOPS, but do not express these characteristic features. Some patients with $\mathrm{RS}_{3} \mathrm{PE}$ may belong to this group. The similarities between $\mathrm{RS}_{3} \mathrm{PE}$ and LOPS have been emphasised elsewhere. ${ }^{18}$

In summary, there undoubtedly exists a condition characterised by a remitting, nonrelapsing symmetrical synovitis with pitting oedema. This may be considered as 'true' $\mathrm{RS}_{3} \mathrm{PE}$. However, quite similar initial clinical features may precede spondyloarthropathy or, to a lesser extent, rheumatoid arthritis, undifferentiated connective tissue disease, or vasculitis. ${ }^{19}$ In this respect, $\mathrm{RS}_{3} \mathrm{PE}$ should be considered as a syndrome rather than a disease. It appears to be related to late onset of the rheumatic diseases. As the underlying disease sometimes requires several years to manifest, long term follow up is indicated in patients with $\mathrm{RS}_{3} \mathrm{PE}$. 
1 McCarty D J, O'Duffy J D, Pearson L, Hunter J B. Remitting seronegative symmetrical synovitis with pitting edema. $\mathscr{F} A M A$ 1985; 254: 2763-7.

2 Amor B, Dougados $M$, Mijiyama $M$. Critères de classification des spondylarthropathies. Rev Rhum Mal Ostéoartic 1990; 57: 85-9.

3 Chaouat D, Le Parc J M. The syndrome of seronegative symmetrical synovitis with pitting edema (RS, PE Syndrome): a unique form of arthritis in the elderly? Report of 4 additional cases. $₹$ Rheumatol $1989 ; 16: 1211-3$.

4 Dubost J J, Sauvezie B. Late onset peripheral spondyloarthropathy. $\mathcal{F}$ Rheumatol 1989; 16: 1214-7.

5 Olivieri I, Oranges G S, Sconosciuto F, Padula A Ruju G P, Pasero G. Late onset peripheral seronegative spondyloarthropathy: report of two additional cases. Rheumatol 1993; 20: 390-3.

6 Leroy E C, Maricq H R, Kahaleh M B. Undifferentiated connective tissue syndromes. Arthritis Rheum 1980; 23: 341-3.

7 Kalliomaki J L, Vastamaki M. Chronic diffuse oedema of the rheumatoid hand A sign of local lymphatic involvement. Ann Rheum Dis 1968; 27: 167-9.

8 Grillet B, Dequeker J. Rheumatoid lymphedema. F Rheumatol 1987; 14: 1095-7.

9 Jayson M I V, Cavill I, Barks J S. Lymphatic clearance rate in rheumatoid arthritis. Ann Rheum Dis 1971; 30: 638-9.

10 Dacre JE, Scott D L, Huskisson E C. Lymphoedema of the limbs as an extra-articular feature of rheumatoid arthritis. Ann Rheum Dis 1990; 49: 722-4.
11 Jayson M I V, Barks J S. Oedema in rheumatoid arthritis: changes in the coefficient of capillary filtration. $B M Y$ 1971; ii: 555-7.

12 Deal C L, Meenan R F, Goldenberg D L, et al. The clinical features of elderly-onset rheumatoid arthritis. Arthritis Rheum 1985; 28: 987-93.

13 Corrigan A B, Robinson R G, Terenty $T$ R, DickSmith J B, Walters $D$. Benign rheumatoid arthritis of the aged. BMF 1974; 1: 444-6.

14 Russell E B, Hunter J B, Pearson L, McCarty D J Remitting, seronegative, symmetrical synovitis with pitting edema- 13 additional cases. $\mathcal{f}$ Rheumatol 1990 pitting edema

15 Woodrow J C. Genetic aspects of the spondyloarthropathies. Clin Rheum Dis 1985; 11: 1-24.

16 Aaron S, Miller M L, Howard J, et al. Complementation with HLA A and HLA D locus alleles in ankylosing spondylitis with peripheral arthritis. $\mathcal{F}$ Rheumatol 1985; 12: 553-7.

17 Sanmarti R, Ercilla M G, Brancos M A, Cid M C, Collado A, Rotes-Querol J. HLA class II antigens (DR, DQ loci) and peripheral arthritis in ankylosing spondylitis. Ann Rheum Dis 1987; 46: 497-500.

18 Javier R M, Sibilia J, Kuntz J L, Asch L. Spondylarthropathie a début tardif? RS3PE? forme de chevauchement? Rev Rhum Mal Osteoartic 1991; 58: 553.

19 Robert W I, Blaivas M. Corticosteroid responsive puffy hands and occult vasculitis neuropathy: $\mathrm{RS}_{3} \mathrm{PE}$ plus? f Rheumatol 1993; 20: 205-6. 